\title{
Trends and seasonal variation of hospitalization and mortality of interstitial lung disease in the United States from 2006 to 2016
}

\author{
An Thi Nhat $\mathrm{Ho}^{1 *}$ (D), Artem Shmelev² and Edward Charbek ${ }^{1}$
}

\begin{abstract}
Background: In the recent years, the overall trends in hospital admission and mortality of interstitial lung disease (ILD) are unknown. In addition, there was some evidence that interstitial lung disease death rate highest in the winter but this finding was only available in one study. This study will investigate the trend and seasonal variations in hospital admission and mortality rates of ILD from 2006 to 2016.

Method: From the Nationwide Inpatient Sample database, we collected all cases with the International Classification of Diseases (ICD)-9 or ICD-10 codes of ILD excluding identifiable external causes (drug, organic or inorganic dusts) from 2006 to 2016. Hospitalization rates of each year were calculated based on U.S Census population data. Monthly hospitalization and in-hospital mortality rates were analyzed by seasonal and trend decomposition. Subgroups of idiopathic interstitial fibrosis (IPF), acute respiratory failure (ARF), pneumonia were analyzed.
\end{abstract}

Results: From 2006 to 2016, all-cause hospital admission rate of patients with interstitial lung disease (ILD) and IPFonly subgroup declined but their overall mortality remained unchanged (except IPF subgroup and acute respiratory failure subgroup). Acute respiratory failure related admission account for $23 \%$ of all causes and pneumonia $17.6 \%$. Mortality of ILD in general and subgroup of ILD with ARF was highest in winter, up to $8.13 \% \pm 0.60$ and $26.3 \% \pm$ $10.2 \%$ respectively. The seasonal variations of hospital admission and mortality of ILD in general was not changed when infectious pneumonia cases were ruled out. All cause admission rates were highest in months from January to April. Subgroup analysis also showed seasonal variations with highest hospitalization rates for all subgroups (IPF, ARF, pneumonia) in the months from December to April (winter to early Spring).

Conclusion: From 2006 to 2016, admission rates of ILD of all causes and IPF subgroup declined but in-hospital mortality of ILD of all causes remained unchanged. Mortality of IPF subgroup and acute respiratory failure subgroup trended down. All-cause hospital admissions and mortality of ILD have a strong seasonal variation. Hospitalization rates for all subgroups (IPF, ARF, pneumonia) were highest in the months from December to April.

Keywords: Interstitial lung disease, Seasonal variation, Mortality, Hospitalization

\footnotetext{
* Correspondence: Nhatan01@gmail.com

'Department of Pulmonary and Critical Care Medicine, Saint Louis University Hospital, Saint Louis, MO, USA

Full list of author information is available at the end of the article
}

(c) The Author(s). 2020 Open Access This article is licensed under a Creative Commons Attribution 4.0 International License, which permits use, sharing, adaptation, distribution and reproduction in any medium or format, as long as you give appropriate credit to the original author(s) and the source, provide a link to the Creative Commons licence, and indicate if changes were made. The images or other third party material in this article are included in the article's Creative Commons licence, unless indicated otherwise in a credit line to the material. If material is not included in the article's Creative Commons licence and your intended use is not permitted by statutory regulation or exceeds the permitted use, you will need to obtain permission directly from the copyright holder. To view a copy of this licence, visit http://creativecommons.org/licenses/by/4.0/. The Creative Commons Public Domain Dedication waiver (http://creativecommons.org/publicdomain/zero/1.0/) applies to the data made available in this article, unless otherwise stated in a credit line to the data. 


\section{Introduction}

Interstitial lung disease (ILD) is a group of lung disorders characterized by abnormalities within the interstitium with or without extensive alteration of alveoli and airways [1]. There have been multiple forms of interstitial lung disease described, most of which lead to progressive lung scarring and dyspnea if left untreated [2, 3]. Idiopathic pulmonary fibrosis (IPF) is one of the most well described ILD with overall very poor prognosis and median survival of 3 to 5 years [4-6]. ILD remains still one of the most challenging respiratory entities to fully understand effectively treat and requires high healthcare utilization. In the past decade, there have been multiple new treatments and knowledge of this complex group of lung disorder. However, study on the overall trend of hospital admission and mortality over the last decade is still needed.

Seasonal variations can play a major role in the general health and wellbeing of patients with respiratory conditions. Winter season can impact lung function and increase the risk of acute exacerbations [7]. The mechanisms of this observation are complex and not fully understood [8]. Pulmonary conditions other than interstitial lung disease such as chronic obstructive pulmonary disease (COPD) have been well studied showing significant seasonal variation [9-11]. Understanding how respiratory diseases change with seasonal variation could guide medical professionals in more effective health resource allocation and to direct future studies on the pathogenesis of this complex entity.

Using a large administrative database, we aimed to analyze the trends and seasonal association of hospital admission and all-cause mortality of ILD in the past 10 years.

\section{Methods}

We obtained the study population from Nationwide Inpatient Sample (NIS) of Agency for Healthcare Resource and Quality (AHRQ) Healthcare Cost and Utilization Project, years 2006 to 2016. All data contained in these database files have previously been de-identified and are off public record, therefore, our institutional review board decided no approval for the study was necessary.

Appropriate weighting was used to produce accurate nation-wide estimates.

Study population was limited to adult patients (age $\geq$ 18 ), admitted with the primary diagnosis of interstitial lung disease (ILD) of all causes excluding the identifiable external causes (drug, asbestos, silicosis, pneumoconiosis, hypersensitivity pneumonitis due to organic dusts). (International Classification of Diseases, ninth revision, clinical modification (ICD-9-CM) diagnostic codes 516.30 through 516.37 and 515); ICD-10-CM codes J84.1 through J84.117). A complete list of used ICD codes with description is available in the Appendix.
Annual population estimates were obtained from U.S Census Bureau, to account for growing U.S population.

\section{Statistical analysis}

Weighted annual and monthly hospitalization and inhospital mortality rates were calculated. Hospitalization rates within each year were calculated based on U.S. Census population estimates for a given year. In-hospital mortality rates were calculated with admission number as denominators and in-hospital death numbers as numerators. Monthly hospitalization or mortality rates represent a time series and can be analyzed by seasonal and trend decomposition procedures to reveal long-term trends, seasonality, and random fluctuations. Seasons were defined in a standard manner ("winter" includes December through February, "spring" - March through May, "summer" - June through August, and "fall" - September through November).

We performed multiple subgroup analyses. The first group included all cases with the primary diagnoses of IDL or PF. In second subgroup, we included only record with interstitial pulmonary fibrosis. Interstitial pulmonary fibrosis cases were identified based on the broad case definition algorithm proposed by Raghu et al. (see the Supplementary Appendix 2). In the third subgroup, we included only record of ILD with acute respiratory failure. The fourth subgroup included ILD with concomitant infectious pneumonia. Please se Appendix section for all ICD codes.

Inter-month and inter-seasonal differences of mean number of hospitalizations was assessed by KruskalWallis rank sum test.

Significance and magnitude of observed annual trends was evaluated by Mann-Kendall test and Sen's slope (Sen PK, 1968).

\section{Results}

\section{Hospital admissions}

Average monthly hospitalization rate per $1,000,000$ population ranges from $6.9 \pm 0.8$ in July to $8 \pm 1.2$ in April. The months from January to April had higher number of admissions compared to the remaining months of the year (Fig. 1). Seasonal pattern of hospitalization rate was the same between subgroups of included and excluded pneumonia.

After merging of months into seasons, mean $( \pm S D)$ number of hospitalizations in spring, summer, fall and winter were $7447.9 \pm 932.0,6643.0 \pm 840.5,6551.3 \pm$ 922.6 and $7110.3 \pm 866.1$ respectively (Fig. 2). Interseasonal differences did not reach statistical significance (ANOVA $p=0.079$ ). However, the difference was found to be significant (independent samples t-test $p$-value $=$ 0.035 ) by comparison of number of hospitalizations during spring (7447.9 \pm 932.0$)$ with other seasons (summer, fall, winter) combined (6768.2 \pm 884.8$)$. 

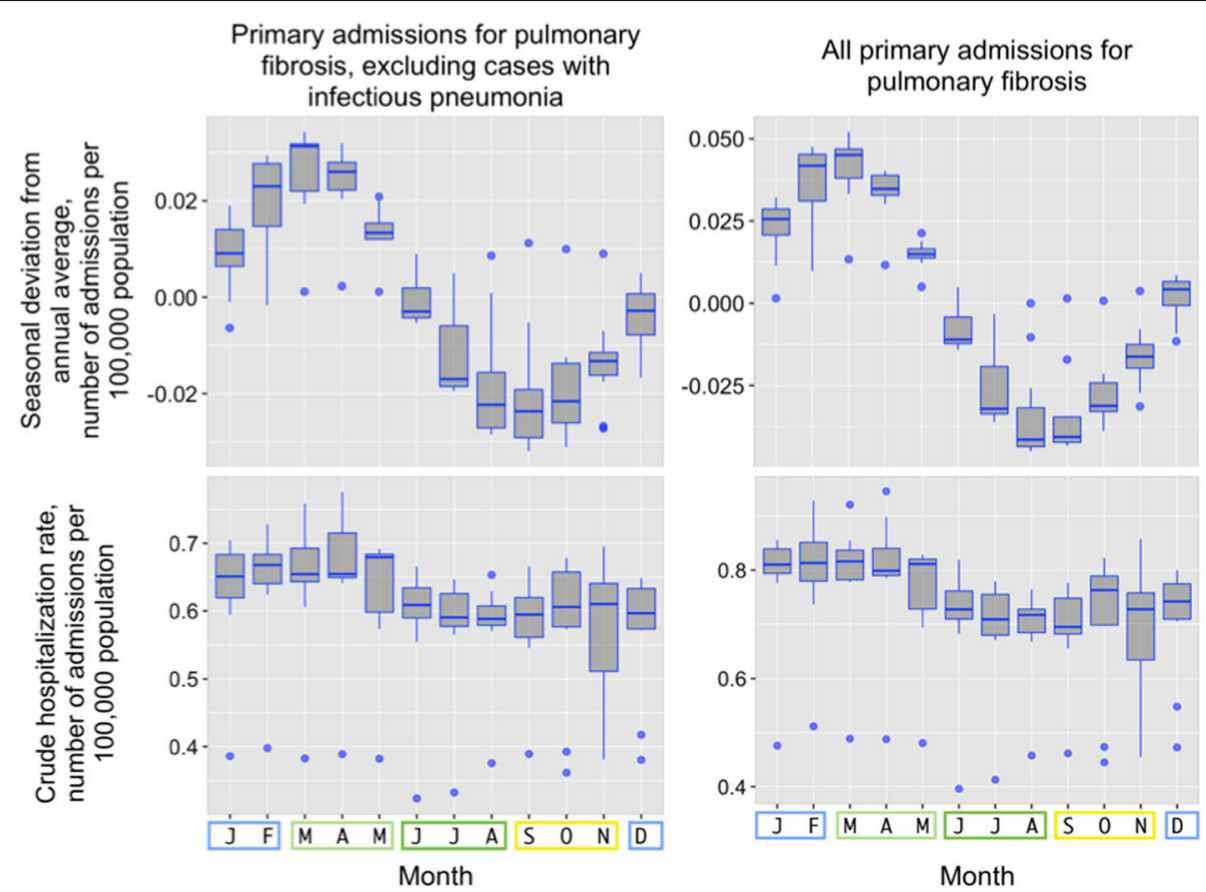

Fig. 1 Crude hospitalization rates for interstitial lung disease (primary diagnosis; per 100,000 population) and seasonal deviation from annual average; including and excluding admissions with PNA

Crude monthly hospitalization rate and trend (by LOESS seasonal decomposition) over 11 years (20062016) is demonstrated in Fig. 3. The observed descending trends were statistically significant $(p<0.001$ on MannKendall test) in both subgroups (with and without exclusion of admissions with PNA). Corresponding Sen's slopes were similar: -0.00133 in group without exclusion of PNA admissions and -0.001167 in group with PNA exclusion. Please note, that National Inpatient Sample switched to ICD-10 system in the third quarter of 2015 database, which could affect reporting of multiple diseases and conditions including PF, despite careful translation of ICD-9 diagnostic codes.

\section{Mortality}

The highest mortality was noted in December and February. The presence or absence of diagnosis of infectious

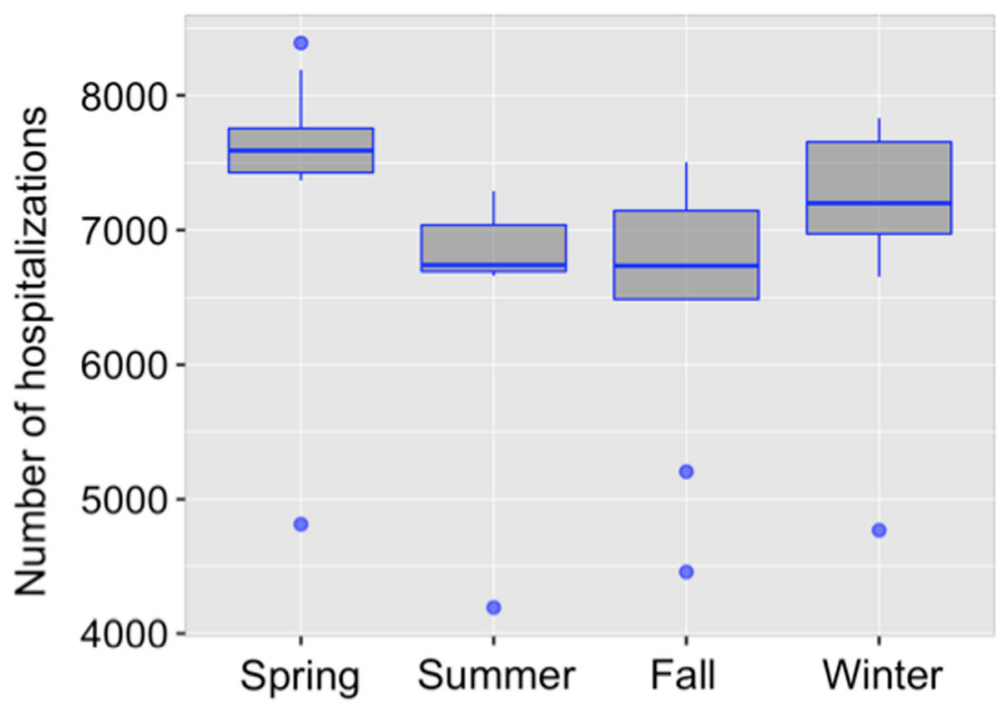

Fig. 2 Number of hospitalizations for ILD grouped by season 


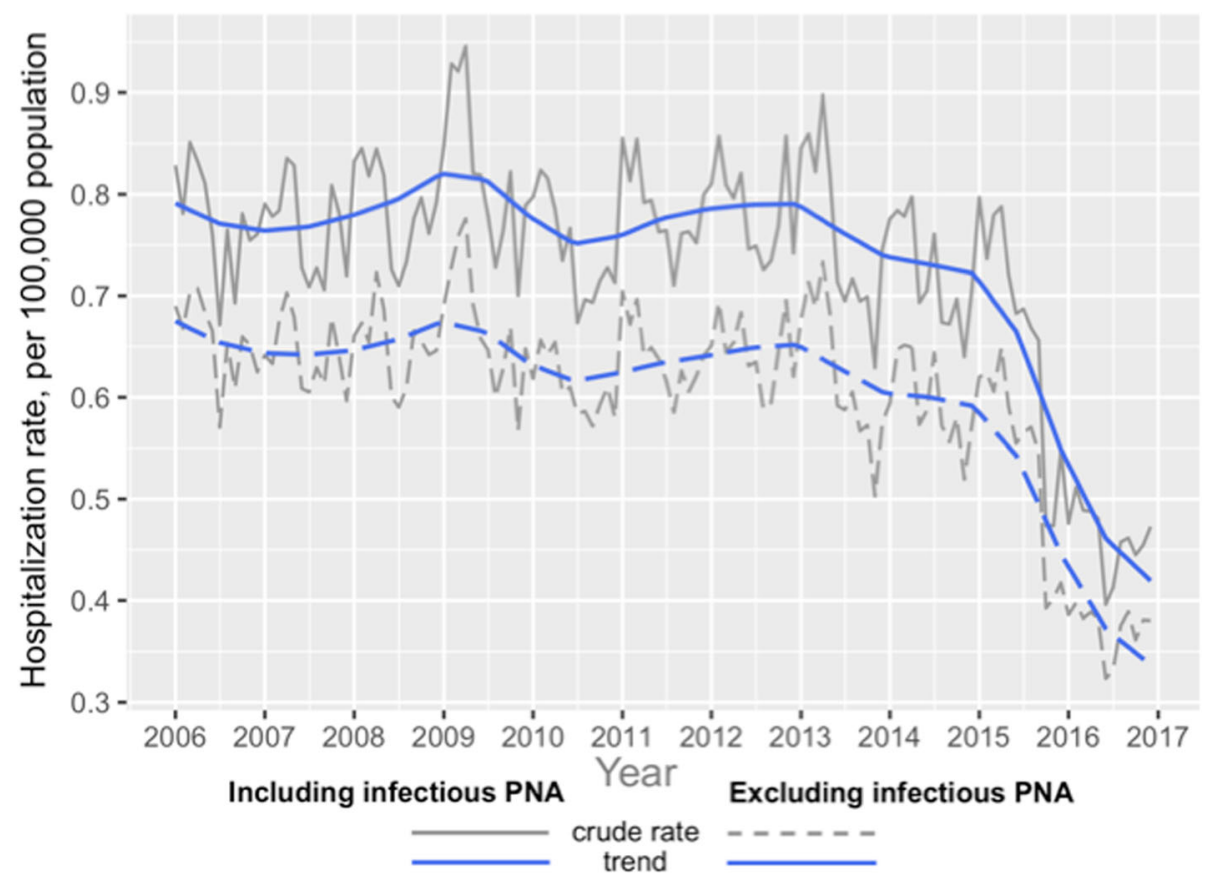

Fig. 3 Crude hospitalization rates for ILD and trend (seasonal LOESS decomposition), per 100,000 population, with and without exclusion of PNA, 2006-2016

pneumonia did not significantly affect seasonal variation of mortality.

Mortality rate in spring, summer, fall and winter were $7.61 \% \pm 0.67, \quad 7.13 \% \pm 0.79, \quad 7.57 \% \pm 0.69$ and $8.13 \% \pm$ $0.60 \%$ respectively (Fig. 4). Observed differences were significant (ANOVA $p=0.018$ ). Again, the highest mortality predisposition to winter was re-demonstrated.

Trend in mortality rate over 11 years are demonstrated in Fig. 5. Observed trends were not significant (MannKendall $p=0.7144$ in subgroup without exclusion of

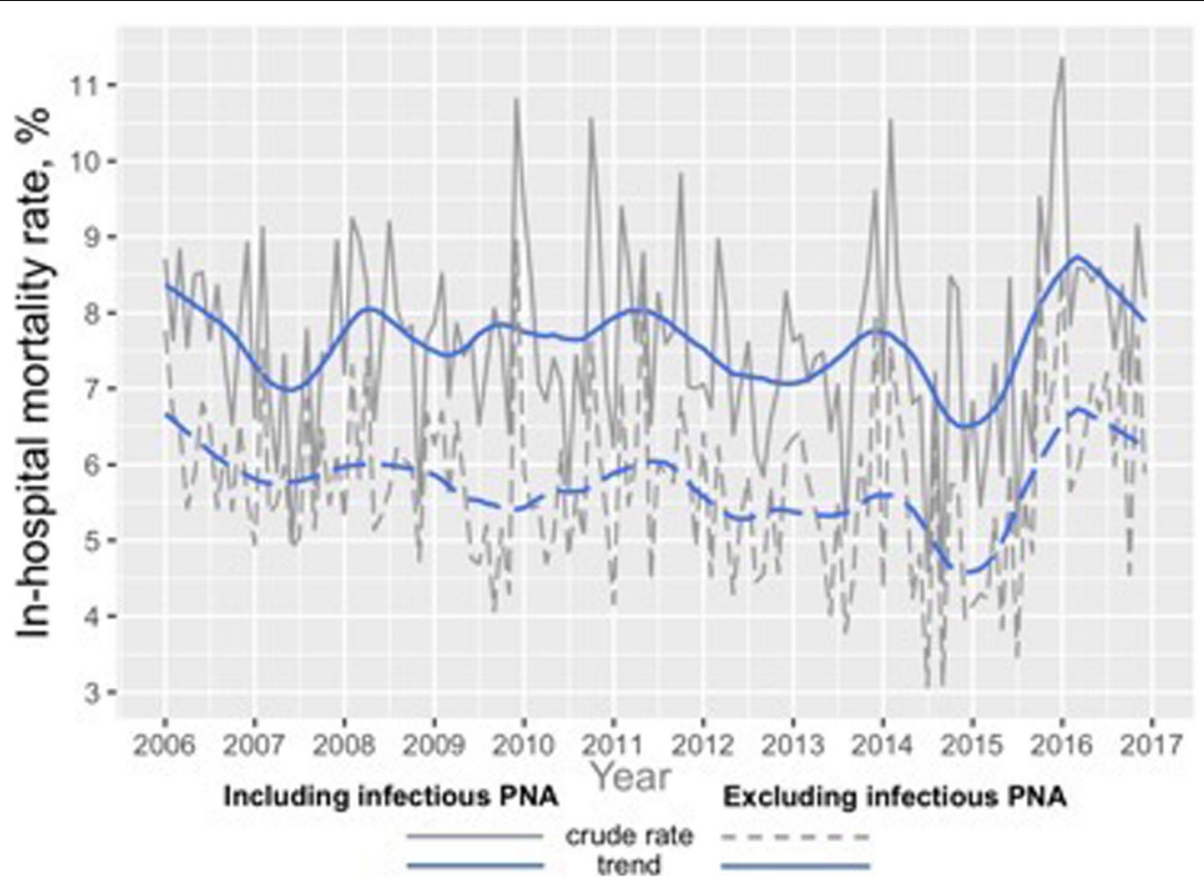

Fig. 4 Crude in-hospital mortality rate and trend (seasonal LOESS decomposition), with and without exclusion of PNA, 2006-2016 


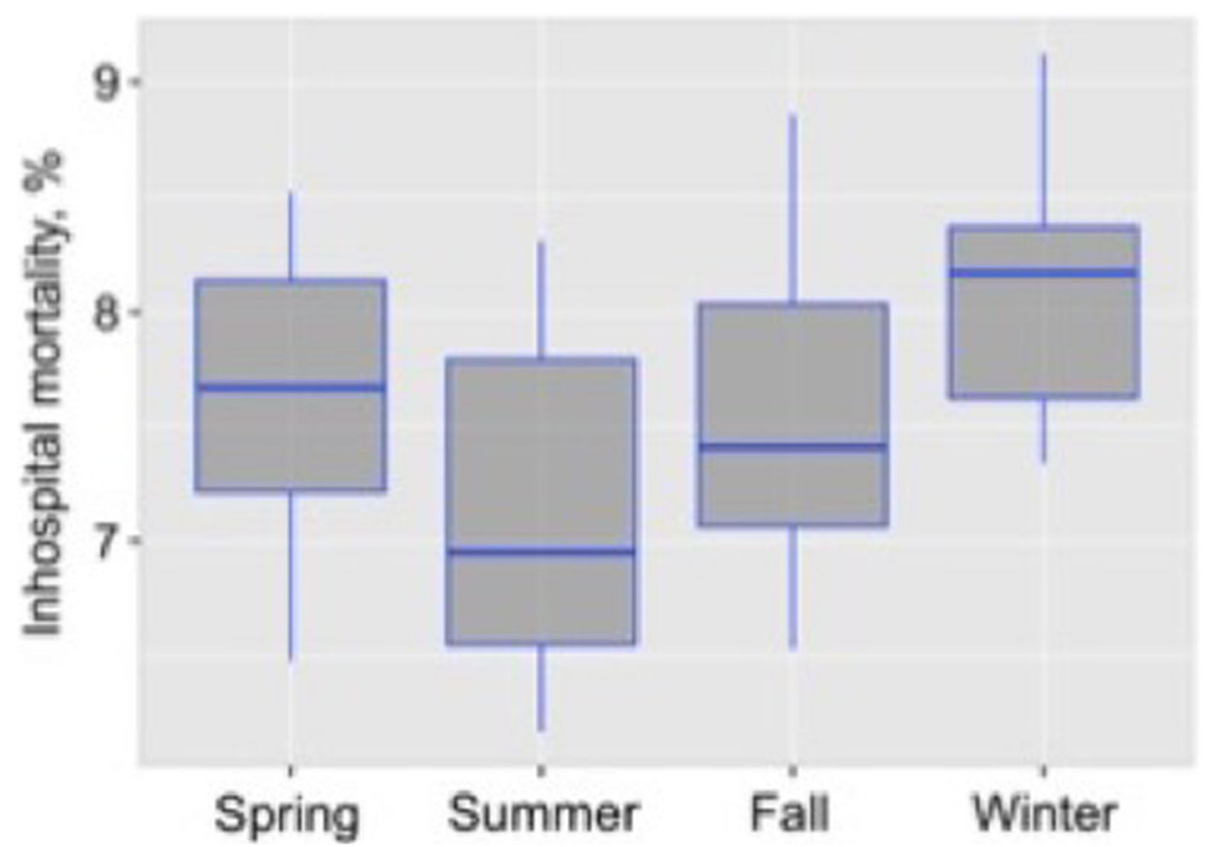

Fig. 5 In-hospital mortality by season, \%

PNA admissions, and 0.2218 in subgroup of excluded PNA admissions).

\section{Subgroups analysis (see figures in supplementary appendix 3) \\ Only idiopathic pulmonary fibrosis (IPF) subgroup}

There was a downward trend in hospitalization and mortality of IPF over 11 years which was statistically significant $(p<0.05)$ (Fig. 6). IPF accounts for $88 \%$ of all admission of interstitial lung disease based on our broad diagnosis algorithm. Hospitalization rate of IPF were noted to be highest in the months from January to April compared to the rest of the months but the mortality rates were not different between months.

\section{Only acute respiratory failure (ARF) as the cause of admission subgroup}

Acute respiratory failure accounts for $23 \%$ of all admission due to interstitial lung disease. Seasonality of hospitalizations and in-hospital mortality did not reach statistical significance on analysis of crude monthly rates, however, seasonal decomposition revealed hidden seasonal variation with slightly higher admission rates in winter. Mortality ranges from $24.2 \% \pm 9.6 \%$ in July to $29.1 \% \pm 11 \%$ in February. Hospitalization rates demonstrated a strong significant up-going trend with almost three-fold increase during 11 years (trend $p<0.001$ ). Mortality decreased at least two-fold with monotonous significant trend $(p<0.001)$ (Fig. 7).
Only pneumonia as the cause of admission subgroup

Admission with the diagnosis of pneumonia accounts for $17.6 \%$ of all admission due to interstitial lung disease. Hospitalization rates in months of December to April were observed to be higher than the remaining months of the year $(p=0.007)$ but mortality did not differ between the months $(p=0.876)$. Hospitalization rate of ILD patients admitted for pneumonia decreased ( $p<$ $0.05)$ but mortality rate remained the same in the period from 2006 to $2016(p=0.756)$

\section{Discussion}

To the best of our knowledge, our study is the first to describe both seasonal variations of hospital admission and in-hospital mortality for IPF and non-IPF ILD in the United States in the 11 year- period from 2006 to 2016. Our primary findings are that from 2006 to 2016, allcause hospital admission rate of patients with interstitial lung disease (all interstitial lung disease and IPF-only subgroup) declined but their overall mortality remained unchanged (except IPF subgroup). Acute respiratory failure related admission account for $23 \%$ of all causes and pneumonia $17.6 \%$. Mortality of ILD in general and ILD with acute respiratory failure is highest in winter, up to $8.13 \% \pm 0.60$ and $26.3 \% \pm 10.2 \%$ respectively. Admission rate for all cause admissions are highest in months from January to April. Subgroup analysis also showed seasonal variations with highest hospitalization rates for all subgroups (IPF, ARF, pneumonia) in the months from December to April (winter to early Spring). 


\section{Crude in-hospital mortality rate and trend (seasonal decomposition using LOESS), primary admissions for IPF, 2006-2016}

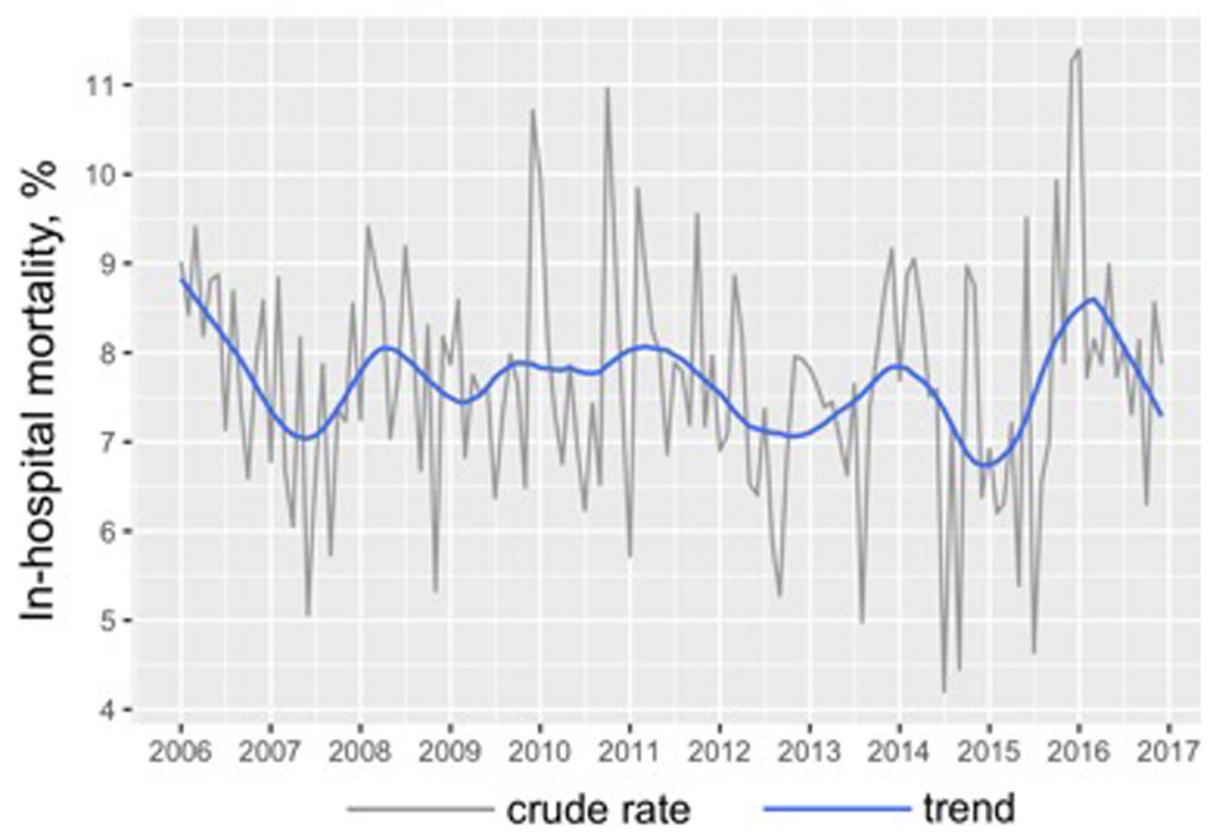

Fig. 6 In-hospital mortality rate and trend with seasonal decomposition of primary admissions for IPF, 2006-2016

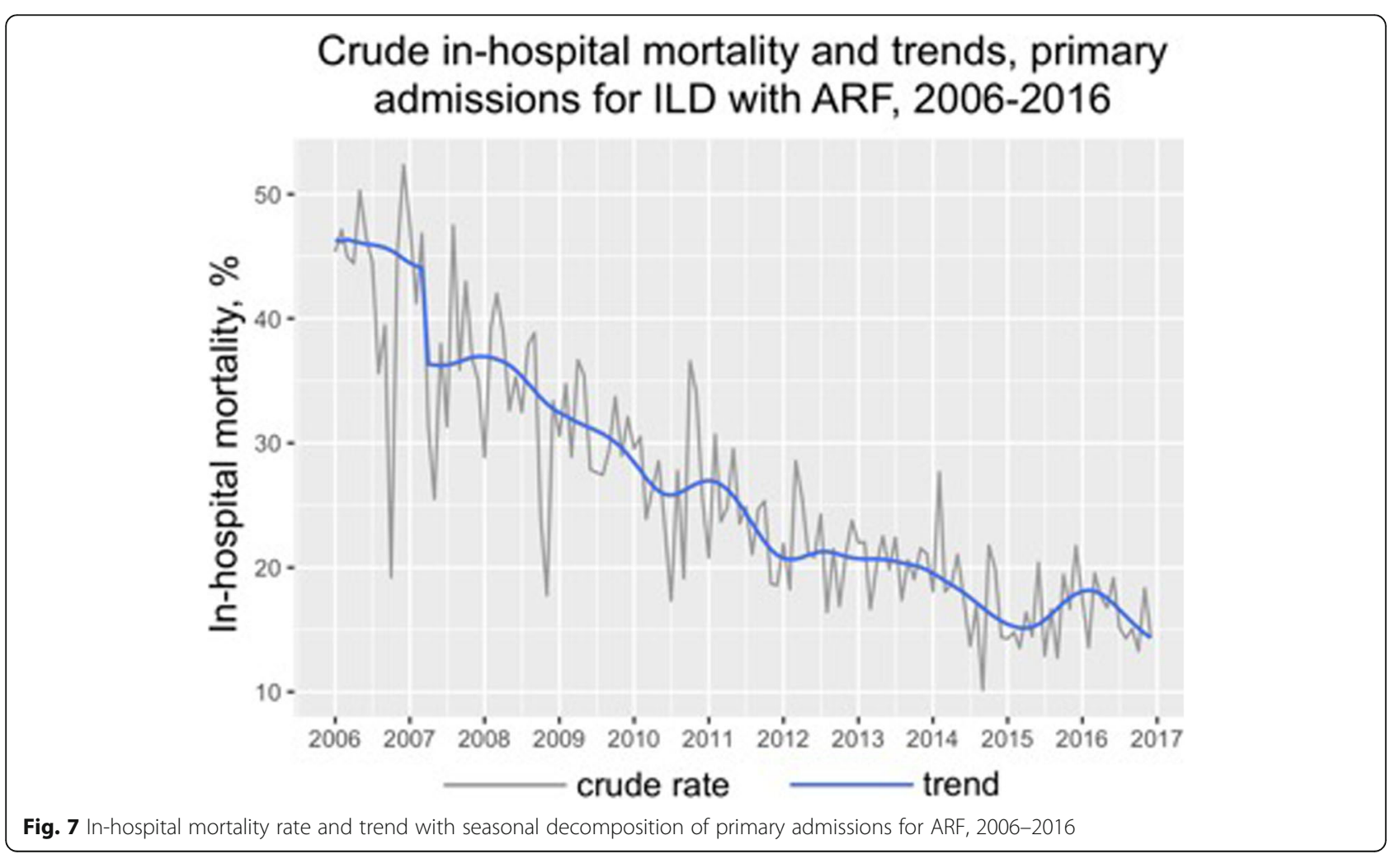


Our finding of highest all-cause mortality for all causes of admissions and subgroup of acute respiratory failure in the winter was similar to the findings by Olson et al. which used a different database for analysis [12]. Seasonal variations were observed in hospitalization rates across all subgroups (acute respiratory failure, IPF, pneumonia) as well. The two most common explanations for winter and early Spring increase in admission rates are respiratory infection and cold temperature. Cold air could hypothetically induce hyperpnoea, subsequently cause drying of the airways [13] and inducing proinflammatory substances production leading to epithelial injury [8]. Infectious etiology was suggested because strong seasonal variations have been reported in COPD, pneumonia and recognized viral illness [14]. There is some evidence that a colder environment could also prolong the life span of viruses. Many viruses such as influenza A, RSV and mycoplasma pneumonia which cause infections in humans almost exclusively in winter to early spring $[15,16]$. One interesting findings is that although winter has highest admission rate for all subgroups (IPF, ARF, pneumonia and ILD in general), the mortality does not have strong seasonal variations in idiopathic pulmonary fibrosis and pneumonia only subgroup. One hypothesis could be the severity of IPF related admissions and pneumonia has no weather association. We could not find literature to explain this finding thoroughly and it could be a topic for future research.

Respiratory causes of death accounted for $64-89 \%$ in patients with ILD [17-19]. We found that acute respiratory failure accounts for $23 \%$ of admission of interstitial lung disease and this types of admission has high mortality rate of $26.3 \% \pm 10.2 \%$. This finding concurs with the results of Moua et al. that IPF and non-IPF interstitial lung disease both have very high and similar mortality rates after admission for respiratory distress [20]. Based on a study in Finland, ischemic heart disease, heart failure and lung cancer were the other causes of death [21]. All of those conditions also have been reported to have higher mortality in winter time in the general population $[12,22]$, which may explain the higher mortality in IPF and non IPF ILD patients in winter time.

Of note, the in-hospital mortality of interstitial lung disease was noted to be significantly higher than the similar study in chronic obstructive lung disease (COPD) and asthma patients using the same national database, $8 \%$ vs $2,8 \%$ vs $1 \%$ respectively [23, 24]. interestingly enough, the mortality rate was $14 \%$ higher in the winter compared to the summer, which was less pronounced than the seasonal variations of all cause of deaths of COPD patients ( 25 to $50 \%$ higher in the winter) [12, 25]. Although both COPD and interstitial lung disease are both progressive illnesses with the pathogenesis involving accelerated cellular senescence [26]. This finding suggests that the impact of weather and viral illness on mortality might not be as pronounced in ILD, compared to COPD.

One of the utmost important roles of physicians is to prevent hospital admission for ILD patients. ILD and especially IPF related admissions are significant events after which the lung function of patients will significantly deteriorate with the mean survival only from 2.8 months to 27.7 months [27]. From our study, we found that all cause admission rates in ILD patients, subgroup of only IPF, acute respiratory failure and only pneumonia in the last 11 years were highest in the months December to April (winter to early Spring). Spring in general had highest admission rates compared to the average of other seasons, even when infectious lung diseases were ruled out. Moineddin et al. in their study in the primary care settings found a higher office visits due to respiratory disease in the months from December to April [28].

In the period of 11 years from 2006 to 2016, we observed a decrease in admissions rate for all cause hospital admission for ILD (all types ILD and subgroup of IPF) with the rise in population taken into account. The sharp decrease in 2016 hospital admissions might be a result of incomplete report of administrative data possibly due to the transition from ICD-10 system in the third quarter of 2015. In addition, many advances have been introduced in diagnosis and treatment of interstitial lung disease [29] as well as in hospital management in reducing hospital admissions [30].

The all-cause mortality rate from interstitial lung disease from 2006 to 2016 has been unchanged. However, the all-cause mortality rate of idiopathic pulmonary fibrosis subgroup encouragingly decreased in this 11-year period. Anti-fibrotic treatment availability could be a possible explanation. A recent large database study by Demsey et al. reported a decreased mortality risk in IPF patients in the first 2 years of anti-fibrotic treatment [31]. However, it is challenging to pinpoint a single factor that lead to this encouraging result based on our study especially when antifibrotic therapies were only approved since 2014 [32].

Our study has limitations. We did not include all types of interstitial lung disease We excluded the interstitial lung disease group with identifiable external agents (organic dust, drug, asbestos, silicosis, pneumoconiosis) because of two reasons. Firstly, it is for the comparison with the results of the study by Olson et al. for the interstitial lung disease group from 1992 to 2003 [12] and secondly, including ILD group with identifiable external agents with different pathogenesis will create more heterogeneity to our population. IPF cases were identified based on a broad definition algorithm which has been 
commonly used in the epidemiology studies. However, this algorithm was sensitive but not specific [33], thus could overestimate the prevalence of IPF in our ILD population. We also did not include the analysis of ILD with and without lung cancer subgroups because it would require extensive analysis beyond the scope of this manuscript. Concomitant lung cancer and interstitial lung disease could be a topic for future studies. Although we have included all ICD-9-CM and ICD-10-CM codes for interstitial lung disease, the results are inevitably susceptible to errors from coding inaccuracies. Nevertheless, this study has provided with an important and objective overview on the seasonal variations and trends in admissions and mortality of this entity spectrum over a long period of time.

\section{Conclusion}

All cause hospital admission and mortality of interstitial lung disease have a strong seasonal variation in 11 years from 2006 to 2016. Hospital admissions are highest in the period from January to May, in-hospital death was highest in the winter. All- cause hospital admission of patients with interstitial lung disease declined but their mortality remained unchanged, with or without the presence of infectious pneumonia.

\section{Supplementary information}

Supplementary information accompanies this paper at https://doi.org/10. 1186/s12931-020-01421-0.

Additional file 1.

Additional file 2.

\section{Abbreviation}

ILD: Interstitial Lung Disease; IPF: Idiopathic Pulmonary Fibrosis; PF: Pulmonary Fibrosis; NIS: Nationwide Inpatient Sample; ICD9CM: International Classification of Diseases, ninth revision, clinical modification

\section{Acknowledgements}

Not available

\section{Authors' contributions}

All authors contributed equally to the manuscript. All authors contributed to the final manuscript and took responsibility for the integrity of the data and the accuracy of the data analysis. An Thi Nhat Ho performed study design, manuscript preparation. Artem Shmelev performed analysis of data and review of manuscript. Edward Charbek designed the study and reviewed the manuscript. The author(s) read and approved the final manuscript.

\section{Funding}

There was no funding for this study.

Availability of data and materials

All data were stored in the national inpatient sample database.

\section{Ethics approval and consent to participate}

This is a study based on large national administrative database that is available for public. Consent and ethics approval was waived and not applicable.
Consent for publication

Not applicable.

\section{Competing interests}

The authors have no conflict of interest and no financial support to disclose.

\section{Author details}

'Department of Pulmonary and Critical Care Medicine, Saint Louis University Hospital, Saint Louis, MO, USA. 'Department of surgery, Saint Agnes Hospital, Baltimore, MD, USA.

Received: 18 March 2020 Accepted: 10 June 2020

Published online: 16 June 2020

\section{References}

1. Bradley B, Branley HM, Egan JJ, Greaves MS, Hansell DM, Harrison NK, Hirani N, Hubbard R, Lake F, Millar AB, et al. Interstitial lung disease guideline: the British Thoracic Society in collaboration with the Thoracic Society of Australia and new Zealand and the Irish thoracic society. Thorax. 2008; 63(Suppl 5):v1-58.

2. Meyer KC. Diagnosis and management of interstitial lung disease. Trans Respir Med. 2014;2:4

3. American Thoracic Society/European Respiratory Society International Multidisciplinary Consensus Classification of the Idiopathic Interstitial Pneumonias. This joint statement of the American Thoracic Society (ATS), and the European Respiratory Society (ERS) was adopted by the ATS board of directors, June 2001 and by the ERS executive committee, June 2001. Am J Respir Crit Care Med. 2002;165:277-304.

4. Hutchinson JP, McKeever TM, Fogarty AW, Navaratnam V, Hubbard RB. Increasing global mortality from idiopathic pulmonary fibrosis in the twenty-first century. Ann Am Thorac Soc. 2014;11:1176-85.

5. Ley B, Collard HR. Epidemiology of idiopathic pulmonary fibrosis. Clin Epidemiol. 2013:5:483-92.

6. Raghu G, Collard HR, Egan JJ, Martinez FJ, Behr J, Brown KK, Colby TV, Cordier JF, Flaherty KR, Lasky JA, et al. An official ATS/ERS/JRS/ALAT statement: idiopathic pulmonary fibrosis: evidence-based guidelines for diagnosis and management. Am J Respir Crit Care Med. 2011;183:788-824.

7. Koskela HO. Cold air-provoked respiratory symptoms: the mechanisms and management. Int J Circumpolar Health. 2007;66:91-100.

8. D'Amato M, Molino A, Calabrese G, Cecchi L, Annesi-Maesano I, D'Amato G. The impact of cold on the respiratory tract and its consequences to respiratory health. Clin Transl Allergy. 2018;8:20.

9. Hansel NN, McCormack MC, Kim V. The effects of air pollution and temperature on COPD. COPD. 2016:13:372-9.

10. Hoffmann C, Hanisch M, Heinsohn JB, Dostal V, Jehn M, Liebers U, Pankow W, Donaldson GC, Witt C. Increased vulnerability of COPD patient groups to urban climate in view of global warming. Int J Chron Obstruct Pulmon Dis. 2018:13:3493-501.

11. So JY, Zhao H, Voelker H, Reed RM, Sin D, Marchetti N, Criner GJ. Seasonal and regional variations in chronic obstructive pulmonary disease exacerbation rates in adults without cardiovascular risk factors. Ann Am Thorac Soc. 2018;15:1296-303.

12. Olson AL, Swigris JJ, Raghu G, Brown KK. Seasonal variation: mortality from pulmonary fibrosis is greatest in the winter. Chest. 2009;136:16-22.

13. Daviskas E, Gonda I, Anderson SD. Mathematical modeling of heat and water transport in human respiratory tract. J Appl Physiol. 1990;69:362-72.

14. Hament JM, Kimpen JL, Fleer A, Wolfs TF. Respiratory viral infection predisposing for bacterial disease: a concise review. FEMS Immunol Med Microbiol. 1999:26:189-95.

15. Tang JW. The effect of environmental parameters on the survival of airborne infectious agents. J R Soc Interface. 2009;6(Suppl 6):S737-46.

16. Monto AS. Epidemiology of viral respiratory infections. Am J Med. 2002; 112(Suppl 6A):4S-12S.

17. Daniels CE, Yi ES, Ryu JH. Autopsy findings in 42 consecutive patients with idiopathic pulmonary fibrosis. Eur Respir J. 2008:32:170-4.

18. Martinez FJ, Safrin S, Weycker D, Starko KM, Bradford WZ, King TE Jr, Flaherty KR, Schwartz DA, Noble PW, Raghu G, et al. The clinical course of patients with idiopathic pulmonary fibrosis. Ann Intern Med. 2005;142:963-7.

19. Collard HR, Moore BB, Flaherty KR, Brown KK, Kaner RJ, King TE Jr, Lasky JA, Loyd JE, Noth I, Olman MA, et al. Acute exacerbations of idiopathic pulmonary fibrosis. Am J Respir Crit Care Med. 2007;176:636-43. 
20. Moua T, Westerly BD, Dulohery MM, Daniels CE, Ryu JH, Lim KG. Patients with fibrotic interstitial lung disease hospitalized for acute respiratory worsening: a large cohort analysis. Chest. 2016;149:1205-14.

21. Karkkainen M, Nurmi H, Kettunen HP, Selander T, Purokivi M, Kaarteenaho R. Underlying and immediate causes of death in patients with idiopathic pulmonary fibrosis. BMC Pulm Med. 2018;18:69

22. Marti-Soler H, Gonseth S, Gubelmann C, Stringhini S, Bovet P, Chen PC, Wojtyniak B, Paccaud F, Tsai DH, Zdrojewski T, Marques-Vidal P. Seasonal variation of overall and cardiovascular mortality: a study in 19 countries from different geographic locations. PLoS One. 2014;9:e113500.

23. Patil SP, Krishnan JA, Lechtzin N, Diette GB. In-hospital mortality following acute exacerbations of chronic obstructive pulmonary disease. Arch Intern Med. 2003;163:1180-6.

24. Kaur BP, Lahewala S, Arora S, Agnihotri K, Panaich SS, Secord E, Levine D. Asthma: hospitalization trends and predictors of in-hospital mortality and hospitalization costs in the USA (2001-2010). Int Arch Allergy Immunol. 2015;168:71-8

25. Wise RA, Calverley PM, Carter K, Clerisme-Beaty E, Metzdorf N, Anzueto A. Seasonal variations in exacerbations and deaths in patients with COPD during the TIOSPIR((R)) trial. Int J Chron Obstruct Pulmon Dis. 2018;13:60516.

26. Chilosi M, Poletti V, Rossi A. The pathogenesis of COPD and IPF: distinct horns of the same devil? Respir Res. 2012;13:3.

27. Brown AW, Fischer CP, Shlobin OA, Buhr RG, Ahmad S, Weir NA, Nathan SD. Outcomes after hospitalization in idiopathic pulmonary fibrosis: a cohort study. Chest. 2015;147:173-9.

28. Moineddin R, Nie JX, Domb G, Leong AM, Upshur RE. Seasonality of primary care utilization for respiratory diseases in Ontario: a time-series analysis. BMC Health Serv Res. 2008;8:160

29. Mori S, Furukawa H, Kawaguchi Y, Suda T, Tasaka S. Current developments in interstitial lung disease. Clin Med Insights Circ Respir Pulm Med. 2015;9: 173-7.

30. Kripalani S, Theobald CN, Anctil B, Vasilevskis EE. Reducing hospital readmission rates: current strategies and future directions. Annu Rev Med. 2014;65:471-85.

31. Dempsey TM, Sangaralingham LR, Yao X, Sanghavi D, Shah ND, Limper AH. Clinical effectiveness of Antifibrotic medications for idiopathic pulmonary fibrosis. Am J Respir Crit Care Med. 2019;200:168-74.

32. Saito S, Alkhatib A, Kolls JK, Kondoh Y, Lasky JA. Pharmacotherapy and adjunctive treatment for idiopathic pulmonary fibrosis (IPF). J Thorac Dis. 2019;11:S1740-54.

33. Ley B, Urbania T, Husson G, Vittinghoff E, Brush DR, Eisner MD, Iribarren C, Collard HR. Code-based Diagnostic Algorithms for Idiopathic Pulmonary Fibrosis. Case validation and improvement. Ann Am Thorac Soc. 2017;14 880-7.

\section{Publisher's Note}

Springer Nature remains neutral with regard to jurisdictional claims in published maps and institutional affiliations.

Ready to submit your research? Choose BMC and benefit from:

- fast, convenient online submission

- thorough peer review by experienced researchers in your field

- rapid publication on acceptance

- support for research data, including large and complex data types

- gold Open Access which fosters wider collaboration and increased citations

- maximum visibility for your research: over $100 \mathrm{M}$ website views per year

At $\mathrm{BMC}$, research is always in progress.

Learn more biomedcentral.com/submissions 